M. Abbasi, N. Slavinskaya, U. Riedel

Kinetic Modeling of Cyclohexane and n-Propylcyclohexane Oxidation with the PAH Precursor Formation, Proc. 56th AIAA Aerospace Sciences Meeting, 08.12.01.2018, Kissimmee, USA

AIAA 2018-0140

The AIAA version of the paper is accessible at

https://doi.org/10.2514/6.2018-0140

On the AIAA web page

http://www.aiaa.org/content.cfm?pageid=2

the interested reader can find other material published by AIAA 


\title{
Kinetic Modeling of Cyclohexane and n-Propylcyclohexane Oxidation with the PAH Precursor Formation
}

\author{
M. Abbasi ${ }^{1}$, N.A. Slavinskaya ${ }^{2}$, U. Riedel ${ }^{3}$ \\ Institute of Combustion Technology, German Aerospace Center (DLR), Stuttgart, Germany
}

\begin{abstract}
A reaction mechanism of cyclohexane $\left(\mathrm{cyC}_{6} \mathrm{H}_{12}\right)$ and n-propylcyclohexane $\left(\mathrm{cyC}_{9} \mathrm{H}_{18}\right)$ is developed to study its oxidation at both low and high temperatures, including $\mathrm{PAH}$ precursors routes. The cyclohexane oxidation kinetic mechanism is a significant update of the model developed earlier in DLR. The new $\mathrm{cyC}_{6} \mathrm{H}_{12}$ model is based on the most recent studied $\mathrm{C}_{0}-\mathrm{C}_{3}$ chemistry and includes the PAH sub-model up to 5-ringed molecules. Improvements have been done through the rivaling the main reaction classes, uncertainty boundaries of the rate coefficients and an inclusion of two additive low-temperature reaction pathways: cyclohexenyl peroxy formation, and isomerization of hydroperoxy peroxy radical. The $\mathrm{cyC}_{6} \mathrm{H}_{12}$ mechanism, successfully validated on the ignition delay data from rapid compression machines (RCM) and shock tube experiments, as well as laminar flame speed data and concentration profiles, model was then further extended to the n-propylcyclohexane oxidation model. For our knowledge, the low-temperature $\mathrm{cyC}_{9} \mathrm{H}_{18}$ oxidation scheme was earlier not presented in the literature. It is shown, that unlike $\mathrm{cyC}_{6} \mathrm{H}_{12}$ the low-temperature ignition of n-propylcyclohexane demonstrates negative temperature coefficient (NTC) behavior. The pathways towards production of benzene as the first aromatics was investigated under the different temperature regimes.
\end{abstract}

\section{Introduction}

DERFORMANCE and in particular emissions of any combustion devices are strongly dependent on the fuel and the underlying chemistry. Practical fuels such as kerosene are complex mixtures of several hundred individual species, which can be divided into four hydrocarbon families (n-/i-paraffins, naphthenes (cyclo-paraffins) and aromatics). Cycloalkanes (naphthenes) are an important chemical class of hydrocarbons found in diesel (up to 35\%), kerosene ( 20\%) and gasoline ( $10 \%)$, which affects the ignition quality of the fuel. Also cycloalkanes can raise soot emission levels because they are known to dehydrogenate and produce aromatics which can initiate the chain reaction for the production of polycyclic aromatics to soot formation and growth. Therefore, kinetic investigation of cyclohexane $\left(\mathrm{cyC}_{6} \mathrm{H}_{12}\right)$ as the simplest naphthene molecule, and n-propylcyclohexane as the most convenient substituted naphthenes in the composition of commercial fuels (especially in jet surrogates) have a great importance in the way predicting the oxidation behavior of conventional fuels and pollution formation.

Despite of numerous investigations [1-21], up to now the published reaction models for $\mathrm{cyC}_{6} \mathrm{H}_{12}$ demonstrate significant discrepancies in the kinetic parameters and results. The uncertainty of reaction rate coefficients for some reaction classes are extremely high and can reach more than 1000 . The ignition delay time measurements performed in the rapid compression machine (RCM) [11, 17] and in the shock tubes (ST) $[16,22]$ report contradictive information: NTC region observed for the $\mathrm{cyC}_{6} \mathrm{H}_{12}$ ignition in the RCM was not detected in the ST experiments.

The n-propylcyclohexane oxidation chemistry is sufficiently less investigated and based on the $\mathrm{cyC}_{6} \mathrm{H}_{12}$ model, consequently takes on every problems of the $\mathrm{cyC}_{6} \mathrm{H}_{12}$ modeling. Only few studies were published $[3,23,24]$ concerning mostly high-temperature oxidation of the $\mathrm{cyC}_{9} \mathrm{H}_{18}$.

In the present paper, the earlier developed [25] $\mathrm{cyC}_{9} \mathrm{H}_{18}$ oxidation model was analyzed and is modified and further developed on the basis of the recently updated and extended $\mathrm{cyC}_{6} \mathrm{H}_{12}$ model [26]. The uncertainty of the key reaction types for both high- and low-temperature scheme have been evaluated. The required thermochemical properties

\footnotetext{
${ }^{1}$ PhD Student, Chemical Kinetics Department, mehdi.abbasi@dlr.de.

${ }^{2}$ Senior research fellow, Chemical Kinetics Department, Nadja.Slavinskaya@dlr.de, AIAA Senior Member

${ }^{3}$ Head of department, Chemical Kinetics Department, uwe.riedel@dlr.de, AIAA Senior Member
} 
specifically for low-temperature species, which have more complex structures, are revised and evaluated, applying Benson's additivity method with new available updates of Benson's groups [27] and ring corrections. The second focus of the paper is the analysis and comparison of the main reaction classes related to the cyclohexane $\left(\mathrm{cyC}_{6} \mathrm{H}_{12}\right)$ and n-propylcyclohexane $\left(\mathrm{cyC}_{9} \mathrm{H}_{18}\right)$ oxidation at lower temperature. This analysis was carried out using the recently published shock tube ignition delay data [22]. Due to the lack of adequate experimental data on species concentration profiles, relevant to n-propylcyclohexane combustion from burn stabilized flame, the routes to production of benzene (A1) as the first substituted aromatics were analyzed at simulation of the auto ignition data for fuel-rich $(\varphi=2)$ and atmospheric pressure conditions.

\section{Kinetic Model}

The current kinetic mechanism implies $\mathrm{C}_{0}-\mathrm{C}_{2}$ chemistry from the recent researches of Slavinskaya et al., [28, 29] the further improvements of the cyclohexane oxidation model developed by Abbasi et al. [26] and the n-propylcyclohexane reactions scheme established in Slavinskaya et al. [25].

The cyclohexane oxidation model of Abbasi et al. [26] were extended with two additive pathways: isomerization of cyOOC ${ }_{6} \mathrm{H}_{10} \mathrm{OOH}$ through the internal hydrogen transfer yielding more stable $\mathrm{cyC}_{6} \mathrm{H}_{9}(\mathrm{OOH})_{2}$ and the secondary low- temperature cyclohexene, $\mathrm{cyC}_{6} \mathrm{H}_{10}$, oxidation. The possible isomers of $\mathrm{cyC}_{6} \mathrm{H}_{9}(\mathrm{OOH})_{2}$ were grouped in a single lumped component, which dissociates into cyclic ketohydroperoxide and $\mathrm{OH}$. This step was included in the scheme to increase the concentrations of less reactive $\mathrm{HO}_{2}$ and cyclohexanone radicals in the intermediate temperature zone.

Cyclohexenyl, $\mathrm{cyC}_{6} \mathrm{H}_{9}$, produced from cyclohexene due to the cascading cyclohexane dehydrogenation, prolongs now the low-temperature cyclohexene oxidation after oxygen addition. This path is competitive with the lowtemperature hexyl oxidation. The developed $\mathrm{cyC}_{6} \mathrm{H}_{12}$ model [26] satisfactorily reproduces the experimental data for ignition delay times, laminar flame speeds and concentration profiles measured in laminar flames. That makes it valuable for the application as a basic model in development of the kinetics schemes for larger and substituted naphthenes.

At the establishment of the sub-model for n-propylcyclohexane oxidation, it was assumed, that, main pathways are determined by its molecular structure and are the combination of the main reaction paths inherent in the cyclohexane and acyclic alkanes $\left(\mathrm{nC}_{3} \mathrm{H}_{7}\right)$ oxidation, and has two regimes of oxidation, high- and low-temperature.

The n-propylcyclohexane high temperature oxidation proceeds through: unimolecular fuel decomposition; $\mathrm{H}$-atom abstraction leading to cycloalkyl radicals, three isomers are consider , ${ }_{9} \mathrm{C}_{9} \mathrm{H}_{17} \mathrm{~A}, \mathrm{cyC}_{9} \mathrm{H}_{17} \mathrm{~B}, \mathrm{cyC}_{9} \mathrm{H} 17 \mathrm{E} ; \beta$-scission decomposition; cascading dehydrogenation leading to benzene and smaller radicals; isomerization and decomposition of linear radicals after the ring-opening step, Fig.1. The related rate constants were evaluated as analogous to those for the cyclohexane and propyl and linear alkane reactions.

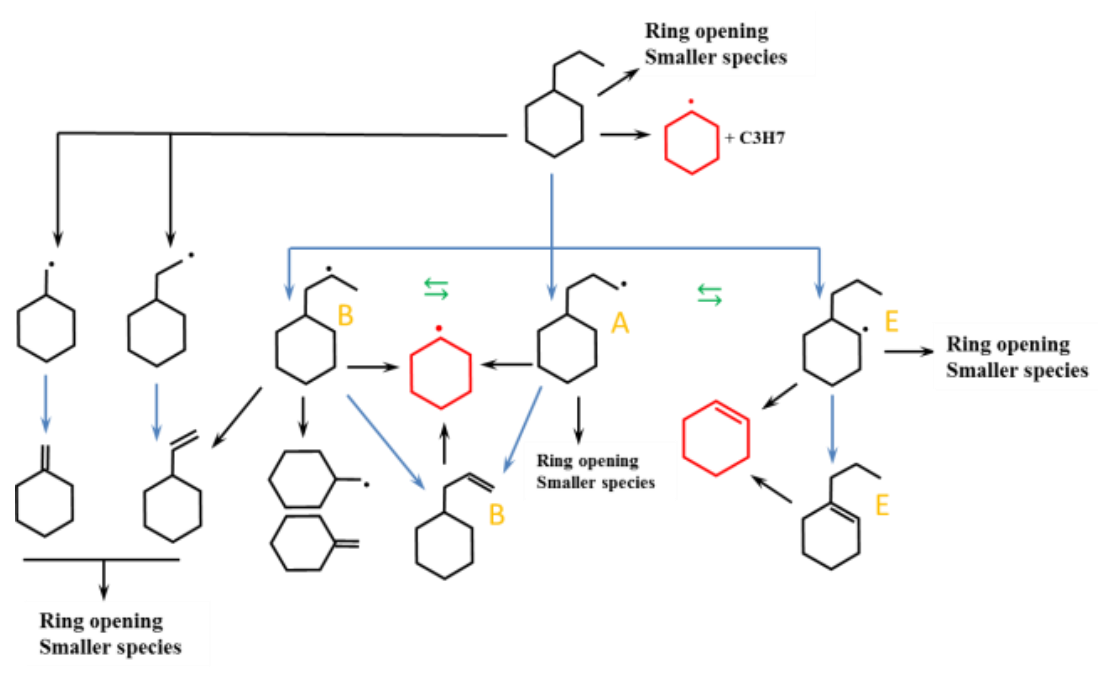

Figure 1. Principal scheme of the high temperature oxidation of $\mathrm{cyC}_{9} \mathrm{H}_{18}$.

For the low-temperature oxidation of n-propylcyclohexane due to the high uncertainties in reaction paths, reaction rate coefficients and reduced number of experimental data, only 7 main reaction paths have been adopted in the reaction mechanism. This our decision follows from the available information related to the low-temperature reactions

American Institute of Aeronautics and Astronautics 
of the cycloalkanes. Table 1 collects the major evaluations/calculations performed for the rate coefficients of cyclohexane and methyl-cyclohexane low-temperature oxidation reactions. As it can be understand, the number of performed investigations is very limited and those related directly to n-propylcyclohexane are critical.

Table 1. Literature evaluations of the reaction coefficients for the low-temperature $\mathrm{cyC}_{6} \mathrm{H}_{12}$ oxidation

\begin{tabular}{|c|c|c|c|}
\hline Ref. & $\mathrm{R}+\mathrm{O}_{2}=\mathrm{ROO}$ & ROO $=\mathrm{QOOH}$ & $\mathrm{ROO}=\mathrm{Q}+\mathrm{HO}_{2}$ \\
\hline Pitz et al. [30] & Analogous to n-alkanes & $\begin{array}{l}\text { Analogous to n-alkanes, } \\
\text { considering corrections in the number } \\
\text { of internal rotors and structure of } \\
\text { transient complexes. }\end{array}$ & \\
\hline Cavalotti et al. [7] & $\begin{array}{l}\text { Quantum chem. } \\
\text { calculations (B3LYP/6- } \\
3 \lg (\mathrm{d}, \mathrm{p}))\end{array}$ & $\begin{array}{l}\text { Quantum chem. calculations } \\
(B 3 L Y P / 6-31 g(d, p))\end{array}$ & $\begin{array}{l}\text { Quantum chem. } \\
\text { calculations (B3LYP/6- } \\
3 \lg (\mathrm{d}, \mathrm{p}))\end{array}$ \\
\hline Silke et al. [8] & $\begin{array}{l}\text { Analogous to n-alkanes, } \\
\text { refers to Pitz et al. [30] }\end{array}$ & $\begin{array}{l}\text { Analogous to n-alkanes with } \mathrm{cyC}_{6} \mathrm{H}_{12} \\
\text { isomerization correction from [30]. }\end{array}$ & $\begin{array}{l}\text { Reduced data of to } \\
\text { Cavalotti et al. [7] with } \\
\text { a factor of } 2 \text {. }\end{array}$ \\
\hline Sirjean et al. [6] & & $\begin{array}{l}\text { Quantum chem. calculations CBS- } \\
\text { QB3 level. }\end{array}$ & \\
\hline
\end{tabular}

On the Figure 2, the finally included in the scheme isomers, and steps of the low-temperature n-propylcyclohexane conversion are demonstrated. These steps proceed through the largely accepted and employed kinetic schemes of the low-temperature alkane oxidation $[31,32]$ with the cyclo-specific and adopted isomer-specific modifications:

1) addition reaction with $\mathrm{O}_{2}$;

2) isomerization of cyclic peroxy cyROO• to cyQOOH• hydroperoxy radical;

3) decomposition of cyQOOH・ to cycloolifene and $\mathrm{HO}_{2}$;

4) decomposition of cycloolifene;

5) $\mathrm{O}_{2}$ addition to cyQOOH$\bullet$ with formation of $\mathrm{O}_{2} \mathrm{QOOH} \bullet$;

6) decomposition of $\mathrm{O}_{2} \mathrm{QOOH} \bullet$ to cyclic ketohydroperoxides;

7) Decomposition of ketohydroperoxides.

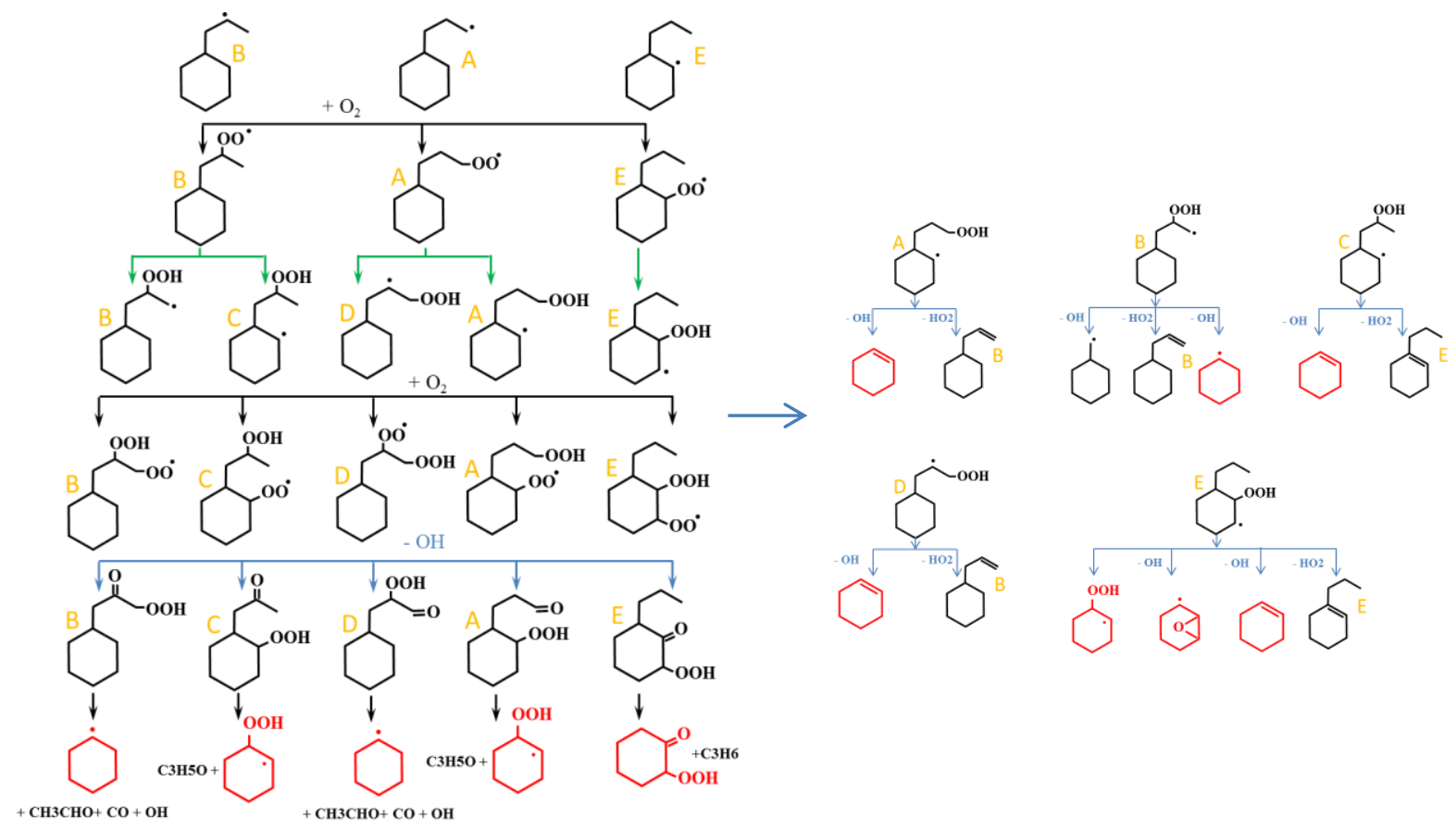

Figure 2. Principal scheme of the low temperature oxidation of $\operatorname{cyC}_{6} \mathrm{H}_{12}$.

American Institute of Aeronautics and Astronautics 
Table 2. Thermodynamic properties of n-propylcyclohexane relevant sub-model species.

\begin{tabular}{|c|c|c|c|c|c|c|c|c|c|}
\hline \multirow{2}{*}{ Species } & \multirow{2}{*}{$\Delta \boldsymbol{H}_{\boldsymbol{f}}^{\mathbf{0}} / \mathrm{kJ} \cdot \mathrm{mol}^{-1}$} & \multirow{2}{*}{$\begin{array}{c}\mathbf{S}^{\mathbf{0}} / \\
\mathrm{J} \cdot \mathrm{mol}^{-1} \cdot \mathrm{K}^{-1} \\
\end{array}$} & \multicolumn{7}{|c|}{$\left.\boldsymbol{C}_{p}(\boldsymbol{T}) / J \cdot \mathrm{mol}^{-1} \cdot \mathrm{K}^{-}\right)$} \\
\hline & & & 300 & 400 & 500 & 600 & 800 & 1000 & 1500 \\
\hline cyC ${ }_{9} \mathrm{H}_{18}$ & -195.17 & 419.15 & 172.74 & 235.72 & 292.28 & 341.56 & 416.46 & 469.92 & 546.57 \\
\hline суC ${ }_{9} \mathrm{H}_{17} \mathrm{~A}$ & -3.73 & 431.54 & 171.91 & 233.19 & 287.57 & 334.59 & 405.61 & 456.07 & 527.98 \\
\hline cyC ${ }_{9} \mathrm{H}_{17} \mathrm{~B}$ & -18.89 & 424.60 & 171.32 & 232.17 & 286.23 & 333.21 & 404.62 & 453.33 & 525.17 \\
\hline суC ${ }_{9} \mathrm{H}_{17} \mathrm{E}$ & -18.92 & 424.59 & 171.35 & 232.22 & 286.29 & 333.29 & 404.98 & 455.30 & 527.65 \\
\hline cyC $\mathrm{C}_{8} \mathrm{H}_{15}$ & -10.96 & 484.26 & 152.48 & 207.05 & 256.30 & 299.52 & 365.98 & 413.19 & 480.82 \\
\hline cyC$_{8} \mathrm{H}_{14}$ & -48.76 & 372.66 & 138.32 & 192.10 & 239.98 & 281.48 & 344.11 & 387.78 & 449.58 \\
\hline $\mathrm{cyC}_{7} \mathrm{H}_{13}$ & 37.13 & 346.94 & 126.17 & 175.07 & 218.63 & 256.39 & 313.34 & 352.88 & 408.91 \\
\hline $\mathrm{cyC}_{7} \mathrm{H}_{12}$ & -35.25 & 329.36 & 120.85 & 165.51 & 206.08 & 241.83 & 296.85 & 335.23 & 388.86 \\
\hline суC ${ }_{9} \mathrm{H}_{17} \mathrm{OOA}$ & -138.99 & 483.18 & 188.79 & 253.36 & 311.34 & 361.76 & 437.84 & 491.51 & 577.42 \\
\hline суC ${ }_{9} \mathrm{H}_{17} \mathrm{OOB}$ & -157.22 & 474.82 & 190.83 & 256.40 & 314.84 & 365.25 & 440.46 & 493.59 & 576.73 \\
\hline $\mathrm{cyC}_{9} \mathrm{H}_{17} \mathrm{OOE}$ & -157.22 & 474.82 & 190.83 & 256.40 & 314.84 & 365.25 & 440.46 & 493.59 & 576.73 \\
\hline $\mathrm{cyC}_{9} \mathrm{H}_{16} \mathrm{OOHA}$ & -97.54 & 503.37 & 203.33 & 267.84 & 323.33 & 371.04 & 444.45 & 494.11 & 570.71 \\
\hline cyC ${ }_{9} \mathrm{H}_{16} \mathrm{OOHB}$ & -80.70 & 498.25 & 210.55 & 274.72 & 329.90 & 377.10 & 448.49 & 495.48 & 567.87 \\
\hline $\mathrm{cyC}_{9} \mathrm{H}_{16} \mathrm{OOHC}$ & -115.77 & 495.01 & 205.37 & 270.89 & 326.82 & 374.52 & 447.07 & 496.19 & 570.03 \\
\hline cyC ${ }_{9} \mathrm{H}_{16} \mathrm{OOHD}$ & -96.05 & 505.29 & 200.74 & 264.91 & 320.20 & 367.84 & 441.87 & 494.69 & 568.21 \\
\hline суC ${ }_{9} \mathrm{H}_{16} \mathrm{OOHE}$ & -96.41 & 491.32 & 209.98 & 273.67 & 328.58 & 375.72 & 447.51 & 494.63 & 567.46 \\
\hline $\mathrm{cyC}_{9} \mathrm{H}_{16} \mathrm{OE}$ & -218.83 & 434.53 & 205.93 & 275.69 & 336.17 & 387.30 & 462.28 & 518.58 & 580.60 \\
\hline суOOC ${ }_{9} \mathrm{H}_{16} \mathrm{OOHA}$ & -235.84 & 553.60 & 222.80 & 292.03 & 351.87 & 402.99 & 479.93 & 532.42 & 619.66 \\
\hline cyOOC ${ }_{9} \mathrm{H}_{16} \mathrm{OOHB}$ & -235.84 & 553.60 & 222.80 & 292.03 & 351.87 & 402.99 & 479.93 & 532.42 & 619.66 \\
\hline $\mathrm{cyOOC}_{9} \mathrm{H}_{16} \mathrm{OOHC}$ & -274.24 & 584.65 & 247.72 & 324.17 & 389.86 & 445.61 & 528.87 & 588.33 & 657.84 \\
\hline $\mathrm{cyOOC}_{9} \mathrm{H}_{16} \mathrm{OOHD}$ & -235.84 & 553.60 & 222.80 & 292.03 & 351.87 & 402.99 & 479.93 & 532.42 & 619.66 \\
\hline суOOC ${ }_{9} \mathrm{H}_{16} \mathrm{OOHE}$ & -274.24 & 584.65 & 247.72 & 324.17 & 389.86 & 445.61 & 528.87 & 588.33 & 657.84 \\
\hline суOC ${ }_{9} \mathrm{H}_{15} \mathrm{OOHA}$ & -375.25 & 509.30 & 213.43 & 277.95 & 332.61 & 379.22 & 450.84 & 499.24 & 574.20 \\
\hline суOC ${ }_{9} \mathrm{H}_{15} \mathrm{OOHB}$ & -375.65 & 511.84 & 215.09 & 282.19 & 337.69 & 384.42 & 456.01 & 503.66 & 577.08 \\
\hline суOC ${ }_{9} \mathrm{H}_{15} \mathrm{OOHC}$ & -404.91 & 513.76 & 210.10 & 274.91 & 329.81 & 376.78 & 449.55 & 498.85 & 577.74 \\
\hline cyOC$_{9} \mathrm{H}_{15} \mathrm{OOHD}$ & -375.25 & 509.30 & 213.43 & 277.95 & 332.61 & 379.22 & 450.84 & 499.24 & 574.20 \\
\hline cyOC $_{9} \mathrm{H}_{15} \mathrm{OOHE}$ & -404.37 & 514.01 & 217.03 & 281.44 & 333.30 & 377.42 & 449.29 & 497.64 & 570.73 \\
\hline cyC ${ }_{9} \mathrm{H}_{16} \mathrm{~B}$ & -70.44 & 412.11 & 161.21 & 221.08 & 274.30 & 320.42 & 390.21 & 439.42 & 509.19 \\
\hline суC ${ }_{9} \mathrm{H}_{16} \mathrm{E}$ & -73.35 & 422.33 & 168.85 & 226.90 & 277.05 & 319.80 & 384.29 & 431.47 & 495.02 \\
\hline
\end{tabular}

The reaction rates of peroxy radicals, $\mathrm{ROO}$ and $\mathrm{OOQOOH}$, following from analogues with acyclic alkanes applying cyclo-specific rate modification rules studied intensively in $[9,30]$ and from recommendations collected in the Table1.

Thermodynamic properties for several cyclic species were newly estimated and revised based on Benson's additivity approach including cyclic and bicyclic ring correction groups, reported in [27], Table 2. For that, properties of some new Benson's groups were estimated, Table 3. 
Table 3. The calculated thermodynamic values for new groups.

\begin{tabular}{|c|c|c|c|c|c|c|c|c|c|c|}
\hline \multirow{2}{*}{ No. } & \multirow{2}{*}{ Group } & \multirow{2}{*}{$\begin{array}{c}\Delta \boldsymbol{H}_{\boldsymbol{f}}^{\mathbf{0}} \\
\mathrm{kJ} \cdot \mathrm{mol}^{-1}\end{array}$} & \multirow{2}{*}{$\begin{array}{c}\boldsymbol{S}^{\mathbf{0}} \\
\mathrm{J} \cdot \mathrm{mol}^{-1} \cdot \mathrm{K}^{-1}\end{array}$} & \multicolumn{7}{|c|}{$\boldsymbol{C}_{\boldsymbol{p}}(\boldsymbol{T}, \boldsymbol{K}) / \mathrm{J} \cdot \mathrm{mol}^{-1} \cdot \mathrm{K}^{-1}$} \\
\hline & & & & 300 & 400 & 500 & 600 & 800 & 1000 & 1500 \\
\hline G1 & $\mathrm{C}-(\mathrm{C} \cdot)(\mathrm{C})(\mathrm{O})(\mathrm{H})$ & -10.77 & -49.75 & 24.63 & 30.87 & 35.06 & 38.28 & 41.67 & 42.00 & 47.20 \\
\hline$G 2$ & $\mathrm{C} \cdot-(\mathrm{O})(\mathrm{H})_{2}$ & 142.50 & 127.10 & 26.19 & 29.00 & 32.90 & 36.16 & 39.90 & 44.04 & 50.15 \\
\hline G3 & $\mathrm{C} \cdot(\mathrm{C})(\mathrm{O})(\mathrm{H})$ & 134.68 & 41.09 & 15.76 & 19.00 & 23.41 & 27.10 & 30.58 & 32.07 & 34.66 \\
\hline G4 & $\mathrm{CO}-(\mathrm{Cd})(\mathrm{C})$ & -146.52 & 52.20 & 24.72 & 29.61 & 34.06 & 37.86 & 41.10 & 42.36 & 45.75 \\
\hline G5 & $\mathrm{C} \cdot-(\mathrm{CO})(\mathrm{H})_{2}$ & 140.44 & 126.21 & 23.82 & 28.55 & 32.60 & 36.08 & 40.40 & 44.06 & 47.91 \\
\hline G6 & $\mathrm{C} \cdot-(\mathrm{Cd})_{2}(\mathrm{H})$ & 81.19 & 25.46 & 16.60 & 24.20 & 30.87 & 35.66 & 40.85 & 45.86 & 50.07 \\
\hline G7 & $\mathrm{C} \cdot-(\mathrm{C})(\mathrm{Cd})(\mathrm{O})$ & 84.01 & -68.99 & 11.28 & 15.32 & 19.97 & 23.24 & 24.86 & 25.52 & 26.06 \\
\hline G8 & $\mathrm{CO}-(\mathrm{C})(\mathrm{H})$ & -123.81 & 137.04 & 29.60 & 33.23 & 37.20 & 41.00 & 46.63 & 50.80 & 56.00 \\
\hline G9 & $\mathrm{CO}-(\mathrm{C} \bullet)(\mathrm{H})$ & -115.24 & 141.92 & 31.31 & 34.83 & 38.37 & 41.72 & 48.73 & 53.61 & 62.35 \\
\hline G10 & $\mathrm{O}-(\mathrm{C} \cdot)(\mathrm{O})$ & -11.51 & 32.92 & 15.40 & 19.63 & 22.25 & 24.71 & 29.69 & 30.80 & 34.62 \\
\hline
\end{tabular}

The non-linear least squares method and its numeric realization FUMILI [33] has been applied to estimate the upper $f_{u}$ and lower $f_{l}$ uncertainty factors for the main reactions:

$$
f_{u}(T)=\log \left[\frac{k_{u p p e r}(T)}{k_{0}(T)}\right], f_{l}(T)=\log \left[\frac{k_{0}(T)}{k_{\text {low }}(T)}\right]
$$

The in house developed tool, named as "Reac-UQ", was used for the mean of quantification of uncertainty intervals. Fig. 3 represents an example of uncertainty analysis for some reactions of high temperature regime.

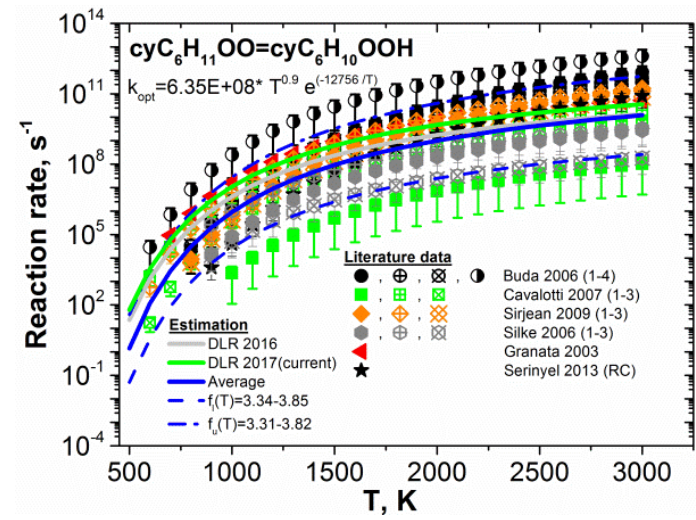

(a)

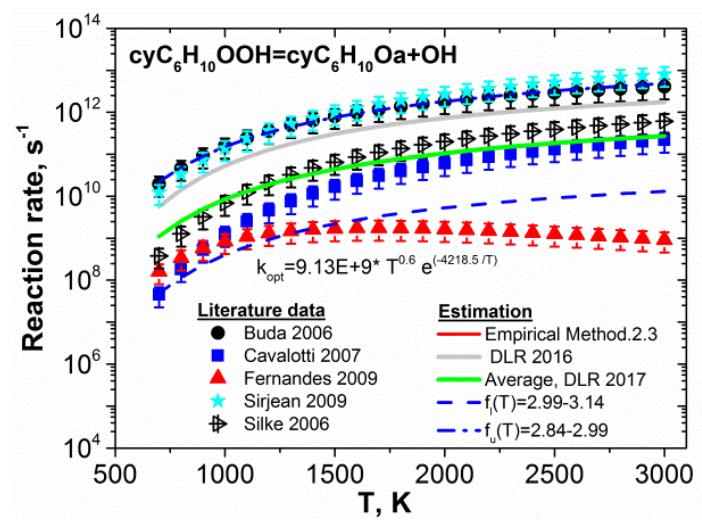

(b)

Figure 3. Uncertainty estimation and analysis of reaction rate vs. temperature, based on the available literature data $[9,7,34,8,35,4]$. (a): numbers in parenthesis count isomers studied in the papers.

The uncertainty factors evaluated for the reactions analysed on the Fig.3, are equal approximately 3-4. The same value were prescribed to the rate coefficients of the n-propylcyclohexane oxidation reaction scheme. Due to the lack of data, it is not able to perform such analysis for $\mathrm{cyC}_{9} \mathrm{H}_{18}$. 


\section{Results and discussion}

The behaviour of the low-temperature cyclohexane and n-propylcyclohexane oxidation models were validated on ignition delay times from rapid compression machines (RCM) [11, 17, 24] and shock tubes experiments (ST) [36] [23, $22]$, over the wide temperature range of $600-1700 \mathrm{~K}$ at various equivalence ratios and pressure ranges.

Figure 4 demonstrates the comparison of the simulated ignition delay times and observed in shock tube [22] under approximatively identical conditions for cyclohexane, Fig. 4a,b, and n-propylcyclohexane, Fig. 4c,d. The simulations and experiments agree well and clearly indicate, that the ignition delay time shape for cyclohexane does not have the negative temperature coefficient, Fig. 4b, while the shape for n-propylcyclohexane demonstrates light NTC behavior, Fig. 4d.
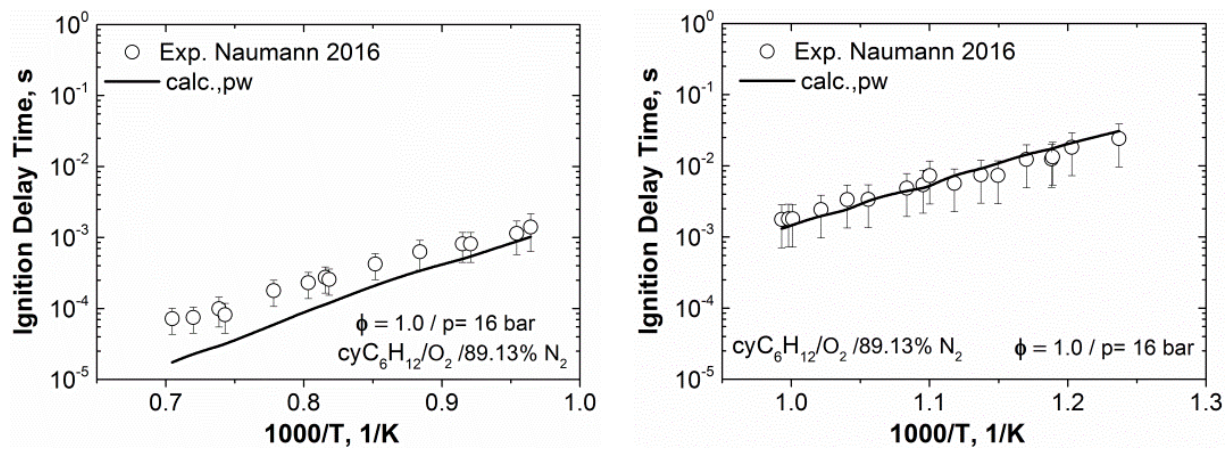

(a)

(b)
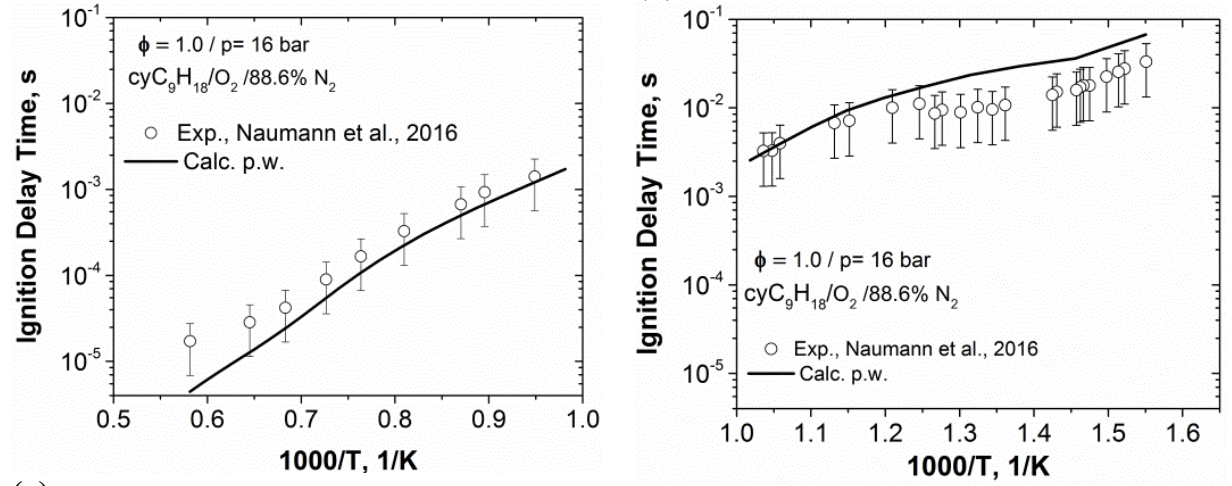

(d)

Figure 4. Comparison of simulated ignition delay times with the ST experiments [22] for stoichiometric mixtures: a),b) cycloxehane; c),d) n-propylcyclohexane.

We analyzed the behavior of the $\mathrm{OH}$ and temperature profiles for both fuels, Fig. 5. It can be clearly see, that unlike $\mathrm{cyC}_{6} \mathrm{H}_{12}, \mathrm{cyC}_{9} \mathrm{H}_{18}$ has peaks on the $\mathrm{OH}$ profile, which correspond to the cool flame and the two stage ignition.

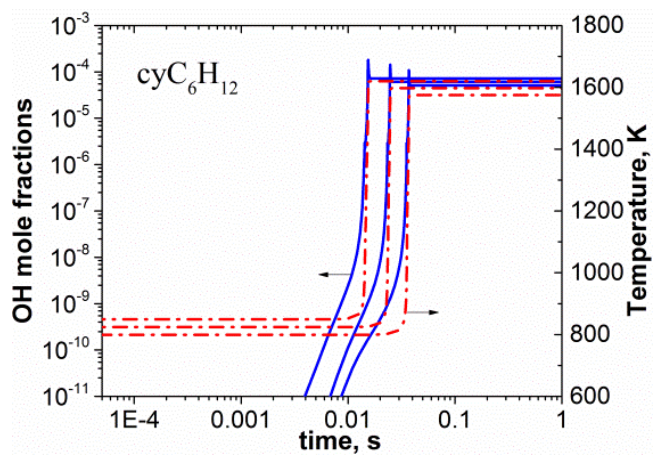

(a)

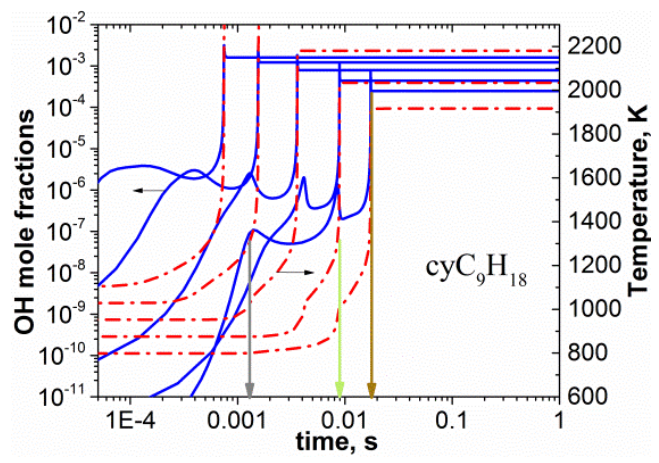

(b)

Figure 5. $\mathrm{OH}$ concentrations and $T$ profiles versus time, for $T_{5}=800-1100 \mathrm{~K}, P_{5}=16 \mathrm{bar}$ :

a) cycloxehane; b) n-propylcyclohexane.

American Institute of Aeronautics and Astronautics 


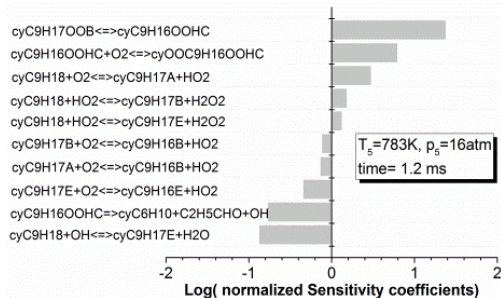

(a)

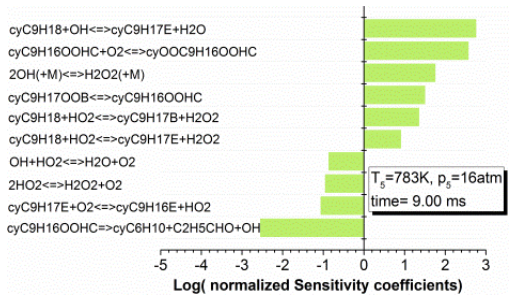

(b)

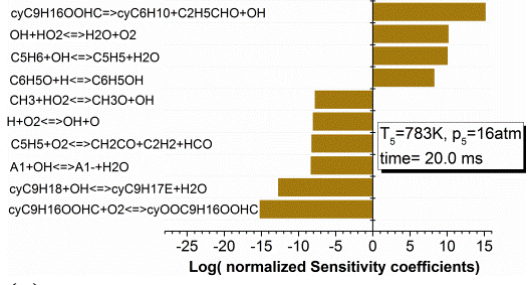

(c)

Figure 6. Normalized sensitivity coefficients of ignition delay times to reactions calculated for the time points marked on the Fig.5b.

How it follows from the rate of production analysis, the first peaks on the $\mathrm{OH}$ concentration profiles are mostly produced in reaction sequences, which are started with the oxygen addition to the $\mathrm{cyC}_{9} \mathrm{H}_{17} \mathrm{~A}$ and $\mathrm{cyC}_{9} \mathrm{H}_{17} \mathrm{~B}, \mathrm{Fig}$.2. The radical $\mathrm{cyC}_{9} \mathrm{H}_{17} \mathrm{E}$ yields in the $\mathrm{OH}$ production with temperature growth. Hereby the peroxy and hydroperoxy radicals,

mostly $\mathrm{cyC}_{9} \mathrm{H}_{17} \mathrm{OOB}$, produced on the substituent group, control the low-temperature oxidation of the $\mathrm{cyC}_{9} \mathrm{H}_{18}$ on the first stages of the chain reaction development. The process evolution is well highlighted with the results of sensitivity analysis performed for three time points, correspond to the $\mathrm{OH}$ and $\mathrm{T}$ arise, marked on the Fig.5. Reactions of the substituted groups control the chain-branching process for the time region of the first and second peaks on the $\mathrm{OH}$ concentration profile, Fig.6a,b. With a temperature increase reactions of $\mathrm{cyC}_{9} \mathrm{H}_{17} \mathrm{OOB}$ become important, Fig.6b,c. Just after ignition, reactions of the aromatic molecules dominate.

One can conclude, that reactions of the substituted groups cause the NTC behavior at the low-temperature oxidation of $\mathrm{cyC}_{9} \mathrm{H}_{18}$. Cyclic peroxy radicals are less reactive, therefore cyclohexane has the gradient change, an acceleration of the overall reaction rate, instead the NTC for intermediate temperatures, Fig. 4a and 4b.

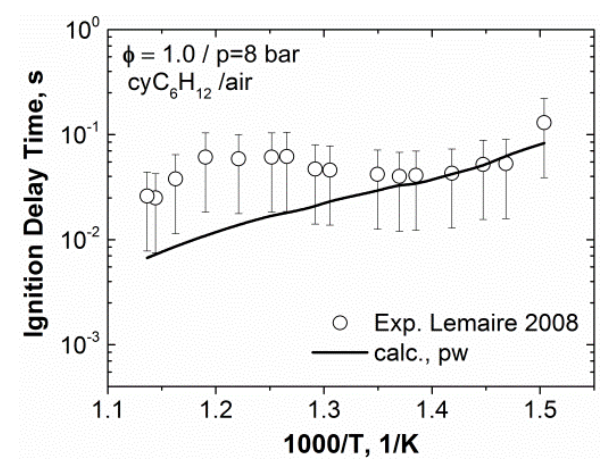

(a)

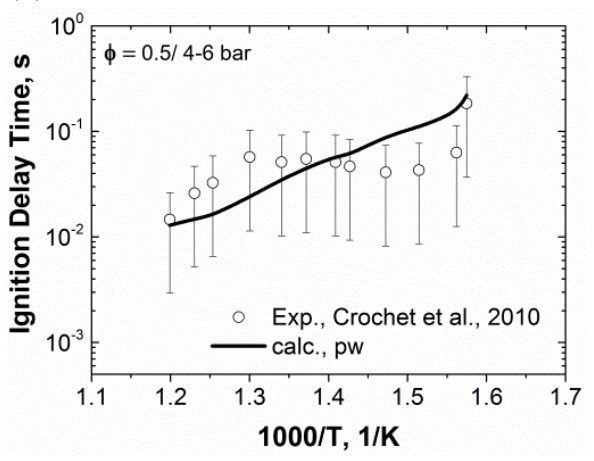

(c)

Figure 7. Comparison of simulated ignition delay times with the RCM experiments [11, 17, 24] for: a),b) cycloxehane; c),d) n-propylcyclohexane.

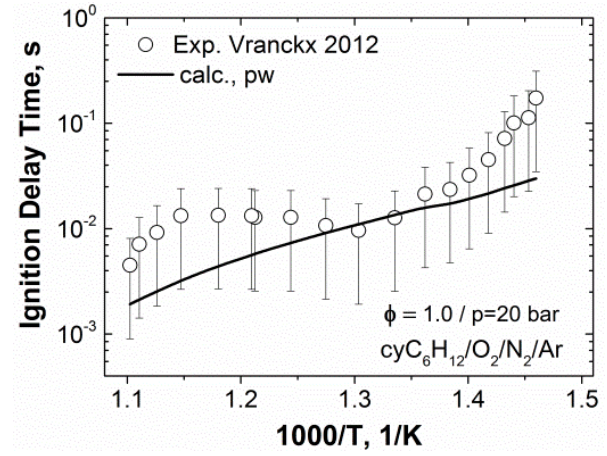

(b)

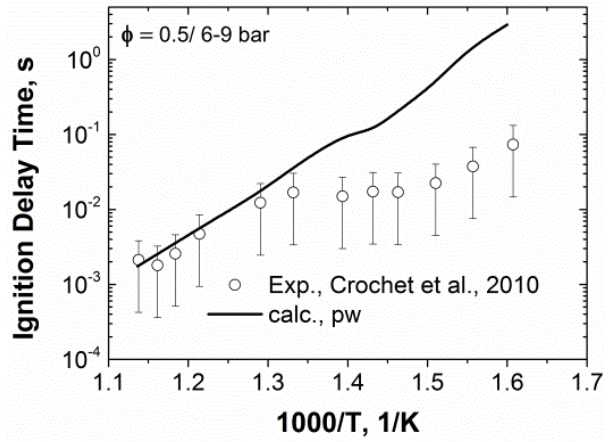

(d) 
Table 4. Adopted reaction rate coefficients.

\begin{tabular}{|c|c|c|c|c|c|}
\hline Reaction path & Isomers & $\mathbf{A}$ & $\mathbf{n}$ & $\mathbf{E a} / \mathrm{cal}$ & Note* \\
\hline \multirow[t]{2}{*}{$\mathrm{R}+\mathrm{O}_{2}=\mathrm{RO}_{2}$} & $\mathrm{~A}, \mathrm{~B}$ & $5.00 \mathrm{E}+19$ & -2.5 & 0.0 & $\mathrm{a}$ \\
\hline & $\mathrm{E}$ & $1.00 \mathrm{E}+19$ & -2.5 & 0.0 & $\mathrm{a}$ \\
\hline \multirow[t]{5}{*}{$\mathrm{RO}_{2}=\mathrm{QOOH}$} & $\mathrm{A} \rightarrow \mathrm{D}$ & $0.50 \mathrm{e}+12$ & 0.0 & 29300 & $\mathrm{~b}$ \\
\hline & $\mathrm{A} \rightarrow \mathrm{A}$ & $2.00 \mathrm{e}+12$ & 0.0 & 24045 & $\mathrm{~b}$ \\
\hline & $\mathrm{B} \rightarrow \mathrm{B}$ & $0.50 \mathrm{e}+12$ & 0.0 & 29300 & $\mathrm{~b}$ \\
\hline & $\mathrm{B} \rightarrow \mathrm{C}$ & $2.00 \mathrm{e}+12$ & 0.0 & 24045 & $\mathrm{~b}$ \\
\hline & $\mathrm{E} \rightarrow \mathrm{E}$ & $2.00 \mathrm{e}+12$ & 0.0 & 24045 & $\mathrm{~b}$ \\
\hline cyQOOH=cy-Olefin+Aldehyde+OH & $\mathrm{A}, \mathrm{C}, \mathrm{D}$ & $1.20 \mathrm{E}+15$ & 0.0 & 22500 & $\mathrm{c}$ \\
\hline cyQOOH=cy-Alkyl+Keton rad.+OH & $\mathrm{B}, \mathrm{D}$ & $1.00 \mathrm{E}+17$ & 0.0 & 35000 & $\mathrm{~d}$ \\
\hline cyQOOH =cy-Olefin $+\mathrm{HO}_{2}$ & A-E & $1.21 \mathrm{E}+13$ & -0.59 & 30800 & $\mathrm{e}$ \\
\hline cyQOOH $=$ cyQ'OOH + Olefin & $\mathrm{E}$ & $2.5 \mathrm{E}+18$ & -0.19 & 30350 & $\mathrm{e}$ \\
\hline cyQOOH=expoxies+OH & $\mathrm{E}$ & $8.00 \mathrm{E}+13$ & 0.0 & 25400 & $\mathrm{f}$ \\
\hline $\mathrm{cyQOOH}+\mathrm{O}_{2}=\mathrm{cyOOQOOH}$ & A-E & $0.50 \mathrm{E}+20$ & -2.5 & 0.0 & $\mathrm{~g}$ \\
\hline cyOOQOOH= cy-Ketohydroperoxy $+\mathrm{OH}$ & A-E & $2.00 \mathrm{e}+12$ & 0.00 & 24045 & $\mathrm{f}$ \\
\hline cy-Ketohydroperoxy decomposition & A-E & $3.30 \mathrm{E}+16$ & 0.00 & 21000 & $\mathrm{~h}$ \\
\hline \multicolumn{6}{|c|}{$\begin{array}{l}\text { *Note: a: modified by analogy with cyclohexane; b: isomerization on internal } \mathrm{H} \text {-transfer on secondary C-atom } \\
\text { [37]; c: analogous to iC8 [38] ; e: analogous to n-alkanes [32,38] f: isomerization } \mathrm{H} \text {-transfer } \mathrm{ROO}=\mathrm{QOOH} \text {; } \\
\text { analogous to } \mathrm{O}_{2} \text { addition h: analogous to } \mathrm{n}-\mathrm{C} 7[32] .\end{array}$} \\
\hline
\end{tabular}

Generally, the NTC region was fixed in the RCM measurements for both, $\mathrm{cyC}_{6} \mathrm{H}_{12}$ and $\mathrm{cyC}_{9} \mathrm{H}_{18}$, Fig.7. The $\mathrm{cyC}_{6} \mathrm{H}_{12}$ model did not reproduce the two stage ignition with NTC behavior, but again an acceleration of the overall reaction rate, wherein simulations lie in the uncertainty boundaries of the measured data [11, 17], Fig.7a,b. The cyC9H18 model demonstrates very weak trend to the NTC regime at the calculations, Fig.7c,d.
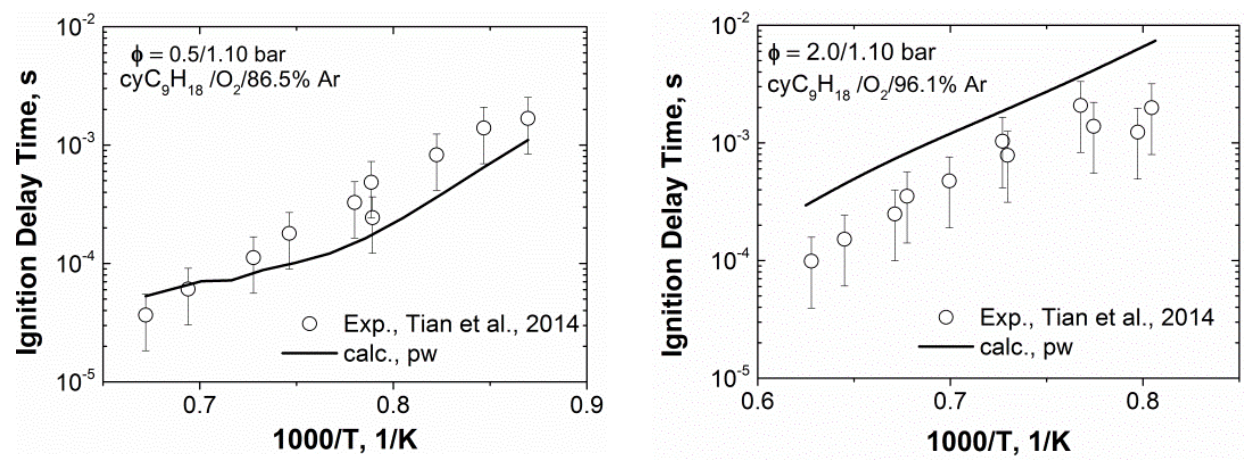

(a)

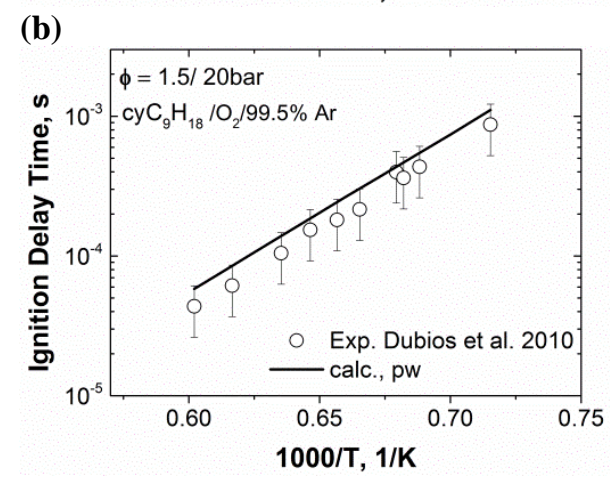

(c)

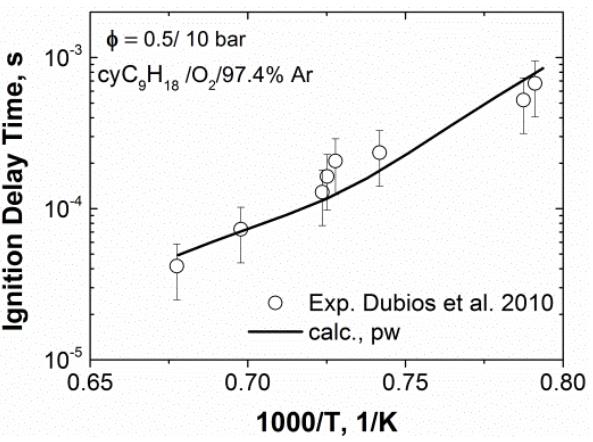

(d)

Figure 8. Comparison of simulated ignition delay times with ST experiments [36, 23] for: n-propylcyclohexane.

The simulations of data [24] lie in the uncertainty boundaries of measurements, Fig.6c, performed for the pressure 4-6 bar and temperature 600-900K. For the similar mixture and temperature range, but for the pressure 6-9 bar, the model overpredicts the experimental data at temperature $600-770 \mathrm{~K}$ with a factor of 10 . We assume, that this

American Institute of Aeronautics and Astronautics 
discrepancy follows from the larger uncertainties of data measured in the rapid compression machines compared to those from shock tubes. These larger uncertainties are an accumulated effect of different well-known factors: the possible reactions in RCM during the compression stroke, heat losses, etc. On this way, for the final $\mathrm{cyC}_{9} \mathrm{H}_{18}$ model optimization and improvement only shock tube experiments were used. In the Table 4, the obtained reaction rate coefficients for the reactions of the low-temperature $\mathrm{cyC}_{9} \mathrm{H}_{18}$ oxidation are collected.

Figure 8 demonstrates further model validation on the shock tube data [36, 23]. Generally the model has good agreement with the experimental data, but overpredicts data for reach mixture [23], Fig.8b.

Due to the lack of adequate experimental data on species concentration profiles, relevant to the n-propylcyclohexane combustion from burn stabilized flame, the auto ignition data from shock tube of Tian et al. [23], measure in fuel-rich condition ( $\varphi=2)$, atmospheric pressure, was utilized to investigate the routes to production of benzene (A1). Figure 9 demonstrates the analysis of the benzene rate of production carried out for time points before and after ignition. Before the ignition takes place $(\mathrm{T}<1500 \mathrm{~K})$, the fuel dissociation and dehydrogenation reactions are the controlling processes for the production of A1, Figure 9a. With temperature increase the production of A1 is mainly influenced by the interactions of small species, specifically $\mathrm{PAH}$ precursors, such as propargyl radical, $\mathrm{i}-\mathrm{C}_{4} \mathrm{H}_{5}, \mathrm{C}_{4} \mathrm{H}_{6}$. But in the postignition zone, at high temperatures, equilibrium of small radical reactions are shifted to the benzene decomposition, Figure $9 \mathrm{~b}$, and only dehydrogenation of fuel yields further in the A1 production.
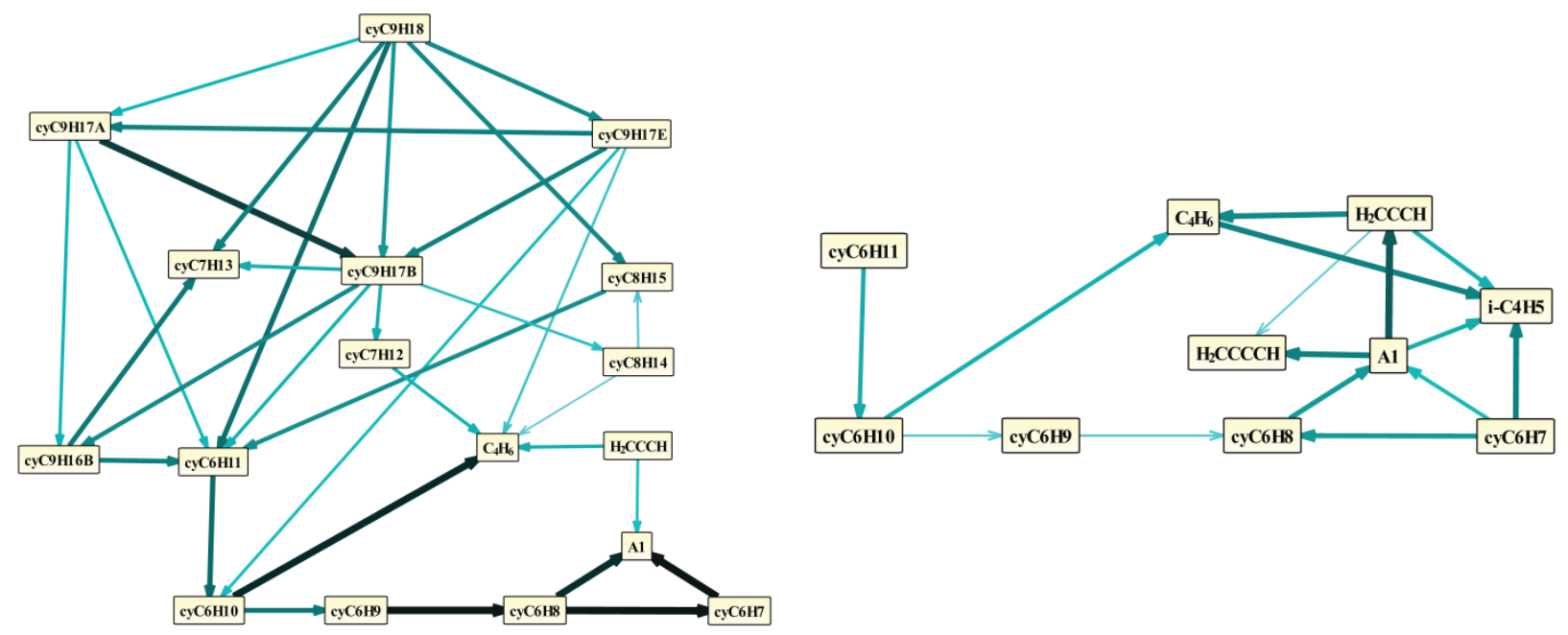

(a)

(b)

Figure 9. Benzene rate of production analysis performed at two different time intervals: a) before ignition b) after ignition. Analysis were carried with the aid of Chemical work Bench software [39] .

\section{Conclusions}

A semi-detailed reaction mechanism for low- and high-temperature cyclohexane and n-proyplcyclohexane oxidation with PAH formation is developed. This mechanism is an improved extension of the cycloalkane oxidation sub-models of DLR hydrocarbon reaction database. In this modified extension, certain number of reaction paths were revised and optimized as the result of uncertainty and sensitivity analyses. It implements a new optimized syngas and acetylene sub model for $\mathrm{C}_{0}-\mathrm{C}_{2}$ chemistry. Special care has been taken to revise of rate parameters specific to cyclic alkanes and to evaluation of uncertainty intervals for the rate coefficients of most important reactions. This analysis revealed that actual uncertainty level of reaction rate coefficients is about 3.5. The low-temperature oxidation pathway of n-propylcyclohexane is developed only with the 7 key paths due to a lack of experimental and thermochemical data available for the n-propylcyclohexane chemistry. The adopted rate coefficients were evaluated with analogous to the acyclic alkanes with the cyclic-specific corrections. The thermodynamical properties of some molecules and radicals were newly calculated with group additivity rule.

The ignition simulations, thermochemistry, flow-rate and sensitivity analyses shown, that unlike cyclohexane, npropylcyclohexane ignition has the NTC region, which is occurred at $800<\mathrm{T}<1100 \mathrm{~K}$ as a response to an increase of overall reactivity initiated by the chain branching reactions of peroxy- and hydroperoxy-radicals produced with substituted group of $\mathrm{cyC}_{9} \mathrm{H}_{18}$. Our numerical simulations are in accordance with the shock tube observations and

American Institute of Aeronautics and Astronautics 
support this conclusion. Species rate of production were also preformed to investigate the influential pathways to formation of the first aromatic ring. It has been seen that under the lower temperature regime production of A1 is mostly ruled by dehydrogenation of the fuel, however in higher temperatures it is mostly controlled by the smaller PAH precursors.

Further investigation of this matter would be very useful for the development of kinetic mechanisms for larger substituted naphthenes.

\section{References}

[1] D. Voisin, A. Marchal, M. Reuillon and J.-C. Boettner, "Experimental and Kinetic Modeling Study of Cyclohexane Oxidation in a JSR at High Pressure," Combustion Science and Technology, vol. 138, pp. 137$158,1998$.

[2] A. El Bakali, M. Braun-Unkhoff, P. Dagaut, P. Frank and M. Cathonnet, "Detailed Kinetic Reaction Mechanism for Cyclohexane Oxidation at Pressure up to Ten Atmospheres," Proceedings of the Combustion Institute, pp. 1631-1638, 2000.

[3] A. Ristori, P. Dagaut, A. El Bakali and M. Cathonnet, "The Oxidation of N-Propylcyclohexane: Experimental Results and Kinetic Modeling," Combustion Science and Technology, pp. 197-228, 2001.

[4] S. Granata, T. Faravelli and E. Ranzi, "A wide range kinetic modeling study of the pyrolysis and combustion of naphthenes," Combustion and Flame, pp. 533-544, 2003.

[5] H. R. Zhang, L. Huynh, N. Kungwan, Z. Yang and S. Zhang, "Combustion Modeling and Kinetic Rate Calculations for a Stoichiometric Cyclohexane Flame.1. Major Reaction Pathways," J. Phys. Chem. A, pp. 41024115, 2007.

[6] B. Sirjean, F. Buda, H. Hakka, P. Glaude, R. Fournet, V. Warth, F. Battin-Leclerc and M. R. Lopez, "The Autoignition of Cyclopentane and Cyclohexane in a Shock Tube," Proceedings of the Combustion Institute, pp. 277-284, 2007.

[7] C. Cavallotti, R. Rota, T. Faravelli and E. Ranzi, "Ab initio evaluation of primary cyclo-hexane oxidation reaction rates," Proceedings of the Combustion Institute, pp. 201-209, 2007.

[8] E. J. Silke, W. J. Pitz, C. K. Westbrook and M. Ribaucour, "Detailed Chemical Kinetic Modeling of Cyclohexane Oxidation," J. Phys. Chem. A, pp. 3761-3775, 2007.

[9] F. Buda, B. Heyberger, R. Fournet, P. Glaude, V. Warth and F. Battin-Leclerc, "Modeling of the Gas-Phase Oxidation of Cyclohexane," Energy \& Fuels, pp. 1450-1459, 2006.

[10] Z. Serinyel, O. Herbinet, O. Frottier, P. Dirrenberger, V. Warth, P. Glaude and F. Battin-Leclerc, "An experimental and modeling study of the low- and high-temperature oxidation of cyclohexane," Combustion and Flame, pp. 2319-2332, 2013.

[11] O. Lemaire, M. Ribaucour, M. Carlier and R. Minetti, "The Production of Benzene in the Low-Temperature Oxidation of Cyclohexane, Cyclohexene, and Cyclohexa-1,3-diene," Combust and Flame, pp. 1971-1980, 2001.

[12] S. G. Davis and C. K. Law, "Determination of and Fuel Structure Effects on Laminar Flame Speeds of C1 to C8 Hydrocarbons," Combustion Science and Technology, pp. 427-449, 1998.

[13] M. E. Law, P. R. Westmoreland, T. A. Cool, J. Wang, N. Hansen and T. Kasper, "Benzene precursors and Formation Routes in a Stoichiometric Cyclohexane Flame," Proceedings of the Combustion Institute, pp. 565573, 2007.

[14] C. Ji, E. Dames, B. Sirjean, H. Wang and F. Egolfopoulos, "An experimental and modeling study of the propagation of cyclohexane and mono-alkylated cyclohexane flames," Proceedings of the Combustion Institute, pp. 971-978, 2011.

[15] F. Wu, A. Kelley and C. Law, "Laminar flame speeds of cyclohexane and mono-alkylated cyclohexanes at elevated pressures," Combust and Flame, pp. 1417-1425, 2012.

[16] S. Daley, A. Berkowitz and M. Oehlschlaeger, "A Shock Tube Study of Cyclopentane and Cyclohexane Ignition at Elevated Pressures," International Journal of Chemical Kinetics, p. 624-634, 2008. 
[17] S. Vranckx, C. Lee, H. Chakravarty and R. Fernandes, "A rapid Compression Machine Study of the Low Temperature Combustion of Cyclohexane at Elevated Pressures," pp. 377-384, 2012.

[18] Z. Hong, K.-Y. Lam, D. Davidson and H. R.K., "A comparative study of the oxidation characteristics of cyclohexane, methylcyclohexane, and n-butylcyclohexane at high temperatures," Combust. Flame, p. 14561468, 2011.

[19] S. Zeppieri, K. Brezinsky and I. Glassman, "Pyrolysis studies of methylcyclohexane and oxidation studies of methylcyclohexane and methylcyclohexane/toluene blends," Combustion and Flame, pp. 266-286, 1997.

[20] A. Ciajolo, A. Tergrossi, M. Mallardo, T. Faravelli and E. Ranzi, "Experimental and Kinetic Modeling Study of Sooting Atmospheric-Pressure Cyclohexane Flame," Proceedings of the Combustion Institute, pp. 585-591, 2009.

[21] S. Richter, M. B. Raida, C. Naumann and U. Riedel, "Measurement of the Laminar Burning Velocity of Neat Jet Fuel Components," Proceedings of the World Congress on Momentum, Heat and Mass Transfer (MHMT'16), Paper No. CSP 115, 2016.

[22] C. Naumann and e. al., "InnoTreib - Innovative Treibstoffe der Zukunft," Bundesministerium für Wirtschaft und Energie (BMWi), Interim reports AP 4.2 and AP 6 from 05.08.2016, 2016.

[23] Z. Tian, Y. Zhang, F. Yang, L. Pan, X. Jiang and Z. Huang, "Comparative Study of Experimental and Modeling Autoignition of Cyclohexane, Ethylcyclohexane, and n-Propylcyclohexane," Energy\&Fuels, pp. 7159-7167, 2014.

[24] M. Crochet, R. Minetti, M. Ribaucour and V. G., "A detailed experimental study of n-propylcyclohexane autoignition in lean conditions," Combustion and Flame, vol. 157, p. 2078-2085, 2010.

[25] N. Slavinskaya, A. Zizin und U. Riedel, „Towards Kerosene Reaction Model Development: Propylcyclohexane, cyC9H18, n-Dodecane, C12H26, and Hexadecane C16H34 Combustion," in 48th AIAA ASM, Orlando, Florida, 2010.

[26] M. Abbasi, N. A. Slavinskaya and U. Riedel, "Kinetic Modeling of Cyclohexane Oxidation Including PAH Formation," Grapevine, Texas, USA, 2017.

[27] S. Benson, Thermochemical Kinetics, 2nd ed., New Yorck, USA: John Wiley \& Sons Ltd., 1976.

[28] N. A. Slavinskaya, M. Abbasi, J. H. Starcke, R. Whitside, A. Mirzayeva, U. Riedel, W. Li, J. Oreluk, A. Hegde, A. Packard, M. Frenklach, G. Gerasimov and O. Shatalov, "Development of an UQ-Predictive Chemical Reaction Model for Syngas Combustion," Energy\&Fuels, vol. 3, pp. 2274-2297, 2016.

[29] Slavinskaya, N.A.; Chernov, V.; Whitside, R.;Starke, J.H.; Mirzayeva, A.; Abassi, M.; Auyelkhankyzy, M., „A modeling study of acetylene oxidation and pyrolisys, " Combustion and Flame, submitted.

[30] W. J. Pitz, C. Naik, T. Ní Mhaoldúin, C. Westbrook, H. J. Curran, J. Orme and J. M. Simmie, "Modeling and experimental investigation of methylcyclohexane ignition in a rapid compression machine," Proc. Combust. Inst., pp. 267-275, 2007.

[31] C. K. Westbrook, J. Warnatz and W. Pitz, "A detailed chemical kinetic reaction mechanism for the oxidation of iso-octane and n-heptane over an extended temperature range and its application to analysis of engine knock," Proc. Combust. Inst., pp. 893-901, 1989.

[32] H. Curran, P. Gaffuri, W. Pitz and C. Westbrook, "A Comprehensive Modeling Study of iso-Octane Oxidation," Combustion and Flame, pp. 253-280, 2002.

[33] Kurbatov, V.S., Silin, I. N., „New method for minimizing regular functions with constraints on parameter region,“ Nucl. Instrum. Methods. Vol. A345, pp. 346-350, 1994.

[34] Sirjean, B., Glaude, P. A., Ruiz-Lopèz, M. F., Fournet, R., „Theoretical Kinetic Study of the Reactions of Cycloalkylperoxy Radicals, “J. Phys. Chem. A,Vol. 113, 2009, pp. 6924-6935.

[35] Fernandes, R.X., Za'dor, J., Jusinski, L. E., Miller, J., A., Taatjes, C. A., „Formally direct pathways and lowtemperature chain branching in hydrocarbon autoignition: the cyclohexyl + $\mathrm{O} 2$ reaction at high pressure, "Phys. Chem. Chem. Phys., 2009, 11, 1320-1327, 2009.

[36] T. Dubois, N. Chaumeix und C. Paillard, „Experimental and Modeling Study of n-Propylcyclohexane Oxidation under Engine-relevant Conditions,“ Energy\&Fuels, Bd. 23, pp. 2453-2466, 2009.

American Institute of Aeronautics and Astronautics 
[37] Handford-Styring,S. M. and Walker, R. W. , „Arrhenius parameters for the reaction $\mathrm{HO} 2$ between + cyclohexane 673 and $773 \mathrm{~K}$, and for H atom transfer in cyclohexylperoxy radicals, "Phys. Chem. Chem. Phys., 2001, 3, 2043-2052.

[38] Ranzi, E., Faravelli, T., Gaffuri,P., Sogaro, A., „A Wide-Range Modeling Study of Iso-Octane Oxidation,“ Combustion and Flame, Vol. 108, 1997, pp. 24-42.

[39] "Chemical Work Bench, Software Package, Ver. 4.1," Kintech Lab, Ltd., [Online]. Available: http://www.kintechlab.com/products/chemical-workbench. [Accessed 2017].

[40] N. Slavinskaya, U. Riedel, S. Dworkin und M. Thomson, Combust. Flame, Bd. 159, Nr. 57, pp. 979-995, 2011.

[41] B. Sirjean, P. A. Glaude, R.-L. M. F. and R. Fournet, "Theoretical Kinetic Study of Thermal Unimolecular Decomposition of Cyclic Alkyl Radicals," J. Phys. Chem. A, pp. 11598-11610, 2008.

[42] G. Dayma, P. A. Glaude, R. Fournet and F. Battin-Leclerc, "Experimental and Modeling Study of the Oxidation of Cyclohexene," International Journal of Chemical Kinetics, vol. 7, pp. 273-285, 2003.

[43] K. Joback and R. Reid, "Estimation of Pure-Component Properties from Group-Contributions," Chemical Engineering Communications, pp. 233-243, 1987.

[44] R. Kee, F. Rupley and J. A. Miller, "Sandia Laboratories Report," Sandia National Laboratories, Albuquerque, NM, 1993.

[45] Y. Zhorov, Thermodynamics of chemical processes, petrochemical, synthesis, processing of petroleum, coal and natural gas, 1 ed., Moscow, Russia: Mir, 1987, p. 248.

[46] M. Trautz and Z. Anorg, "Evaluation of Arrhenius Frequency Factor (A) by Simple Collision Theory," Chemistry, vol. 1, 1916.

[47] G. Chernyi, S. Losev, S. Macheret and B. Potapkin, Physical and Chemical Processes in Gas Dynamics : Cross Sections and Rate Constants: American Institute of Aeronautics \& Astronautics, 20 Jun 2002., Reston, United States: AIAA, 2012.

[48] E. Ranzi, T. Faravelli, P. Gaffuri and A. Sogaro, "A Wide-Range Modeling Study of Iso-Octane Oxidation," Combustion and Flame, vol. 108, pp. 24-42, 1997.

[49] D. Matheu, W. H. Green and J. Grenda, "Capturing pressure-dependence in automated mechanism generation: Reactions through cycloalkyl intermediates," Int. J. Chem. Kinet., p. 95, 2003.

American Institute of Aeronautics and Astronautics 